\title{
Concrete Failure Modeling Based on Micromechanical Approach Subjected to Static Loading
}

\author{
Endah Wahyuni ${ }^{1}$
}

\begin{abstract}
In this paper, a micromechanical model based on the Mori-Tanaka method and the spring-layer model is developed to study the stress-strain behavior of concrete. The concrete is modeled as a two-phase composite. And the failure of concrete is categorized as mortar failure and interface failure. The research presents a method for estimating the modulus of concrete under its whole loading process. The proposed micromechanical model owns the good capabilities for predicting the entire response of concrete under uniaxial compression. It is suitable that tensile strain is as the criterion of concrete failure and the prediction of crack direction also fits with experimental phenomenon.
\end{abstract}

Keywords-Mori-Tanaka method, interface, mortar, Weibull distribution

\section{INTRODUCTION}

$\mathrm{R}$ ecently some researchers studied the elastic properties of concrete using the micromechanical model [1]. The interface zone is usually considered as a new elastic phase. However, concrete contains many microcracks, especially in the interface zone, even before any loading is applied (Fig. 1). Some experiments have shown that the matrix just surrounding the aggregate is found to have quite different stiffness properties than that away from the aggregate[2]. Here concrete is considered as a kind of two-phase composite (the mortar and coarse aggregates). They are bonded together by the interface zone. Softening of concrete is considered as the appearance and development of microcracks.

\section{BASIC FORMULATION}

In the Mori-Tanaka method, consider an infinitely extended mortar medium $D$ containing many spherical inclusions (coarse aggregates) with an imperfectly bonded interface (Fig. 2). The elastic stiffness of the mortar and coarse aggregate are $\mathrm{L}_{0}$ and $\mathrm{L}_{1}$. Homogeneous boundary condition in the external surface $S$ of $D$ is employed:

$\sigma_{\mathrm{n}}(S)=\sigma^{0} . n$

where $\sigma^{0}$ is constant stress tensor, and $n$ denotes the external normal to the external surface $S$. If the solid did not contain any inhomogeneity, the strain field would be $\varepsilon^{0}=L_{0}{ }^{-1} \cdot \sigma^{0}$

The stress and strain in mortar differ from $\sigma^{0}$ and $\varepsilon^{0}$ by $\widetilde{\sigma}$ and $\widetilde{\varepsilon} \cdot \widetilde{\varepsilon}$ is the perturbed strain due to the presence of all the coarse aggregates. The average stress is $\bar{\sigma}^{(0)}=\sigma^{0}+\widetilde{\sigma}=L_{0}\left(\varepsilon^{0}+\widetilde{\varepsilon}\right)$

${ }^{1}$ Endah Wahyuni is with Department of Civil Engineering, FTSP, Institut Teknologi Sepuluh Nopember, Surabaya, 60111, Indonesia. E-mail: endah@ce.its.ac.id.
The stress and strain of the coarse aggregates experience further perturbations from those of the surrounding mortar by $\sigma^{p t}$ and $\varepsilon^{p t}$. The average stress in aggregate is

$$
\begin{aligned}
\bar{\sigma}^{(1)} & =\sigma^{0}+\widetilde{\sigma}+\sigma^{p t} \\
& =L_{1}\left(\varepsilon^{0}+\widetilde{\varepsilon}+\varepsilon^{p t}\right) \\
& =L_{0}\left(\varepsilon^{0}+\widetilde{\varepsilon}+\varepsilon^{p t}-\varepsilon^{*}\right)
\end{aligned}
$$

here $\varepsilon^{*}$ is the equivalent transformation strain.

There is an assumption that the two sides of interface always are connected with each other so there is only the displacement jump. The interfacial traction remains continous, while both the normal and the tangential displacements might experience a jump across the interface [3]. The interface conditions is

$\left[\sigma_{\mathrm{ij}}\right] n_{\mathrm{j}}=0$

$\left[u_{\mathrm{i}}\right]\left(\delta_{\mathrm{ik}}-n_{\mathrm{i}} n_{\mathrm{k}}\right)=\alpha_{\mathrm{T}} \cdot T_{\mathrm{k}}$

$\left[u_{\mathrm{i}}\right] n_{\mathrm{i}} n_{\mathrm{k}}=\alpha_{\mathrm{N}} \cdot \mathrm{N}_{\mathrm{k}}$

In which $\alpha_{\mathrm{T}}$ and $\alpha_{\mathrm{N}}$ denote the compliance in the tangential and the normal directions. [.] $=($ out $)-($ in $), n_{i}$ is the outward unit normal on the interface, and $T_{i}=$ $\sigma_{k j} \cdot n_{j}\left(\delta_{i k}-n_{i} n_{k}\right)$ and $N_{i}=\sigma_{k j} \cdot n_{k} \cdot n_{j} \cdot n_{i}$ represent the shear and the normal tractions. $\delta_{\mathrm{ij}}$ is the Kronecker $\delta . \alpha_{T}$ and $\alpha_{N}$ should be positive.

For the coarse aggregates with imperfect interface, we have the relationship between the eigenstrain and perturbation strain in coarse aggregates is

$\varepsilon_{\mathrm{ij}}^{\mathrm{pt}}=S_{\mathrm{ijk} \mathrm{l}} \cdot \varepsilon_{\mathrm{kl}}{ }^{*}$

where

$S_{i j k l}=S_{i j k l}^{E}+S_{i j k l}^{S}$

Here $S_{i j k l}^{E}$ is Eshelby's solution for uniform eigenstrain problem of inclusion with perfectly bonded interface. For the spherical inclusion, it gives

$S_{i j k l}^{E}=\frac{1}{2} \beta^{E}\left(\delta_{i k} \delta_{j l}+\delta_{i l} \delta_{j k}\right)+\frac{1}{3}\left(\alpha^{E}-\beta^{E}\right) \delta_{i j} \delta_{k l}$

with

$S_{1111}^{E}=S_{2222}^{E}=S_{3333}^{E}=\frac{7-5 v_{0}}{15\left(1-v_{0}\right)}$,

$S_{1122}^{E}=S_{2233}^{E}=S_{3311}^{E}=S_{1133}^{E}=S_{2211}^{E}=S_{3322}^{E}=\frac{5 v_{0}-1}{15\left(1-v_{0}\right)}$,

$S_{1212}^{E}=S_{2323}^{E}=S_{3131}^{E}=\frac{4-5 v_{0}}{15\left(1-v_{0}\right)}$.

where

$\alpha^{E}=\frac{1+v_{0}}{3\left(1-v_{0}\right)} \quad, \quad \beta^{E}=\frac{2\left(4-5 v_{0}\right)}{15\left(1-v_{0}\right)}$

Here $v_{0}$ is Poisson's ratio of cement paste. If there is an infinite medium $D$ containing a uniform eigenstrain $\varepsilon_{\mathrm{ij}}{ }^{*}$ in a spherical inclusion $\Omega$ with an imperfectly bonded 

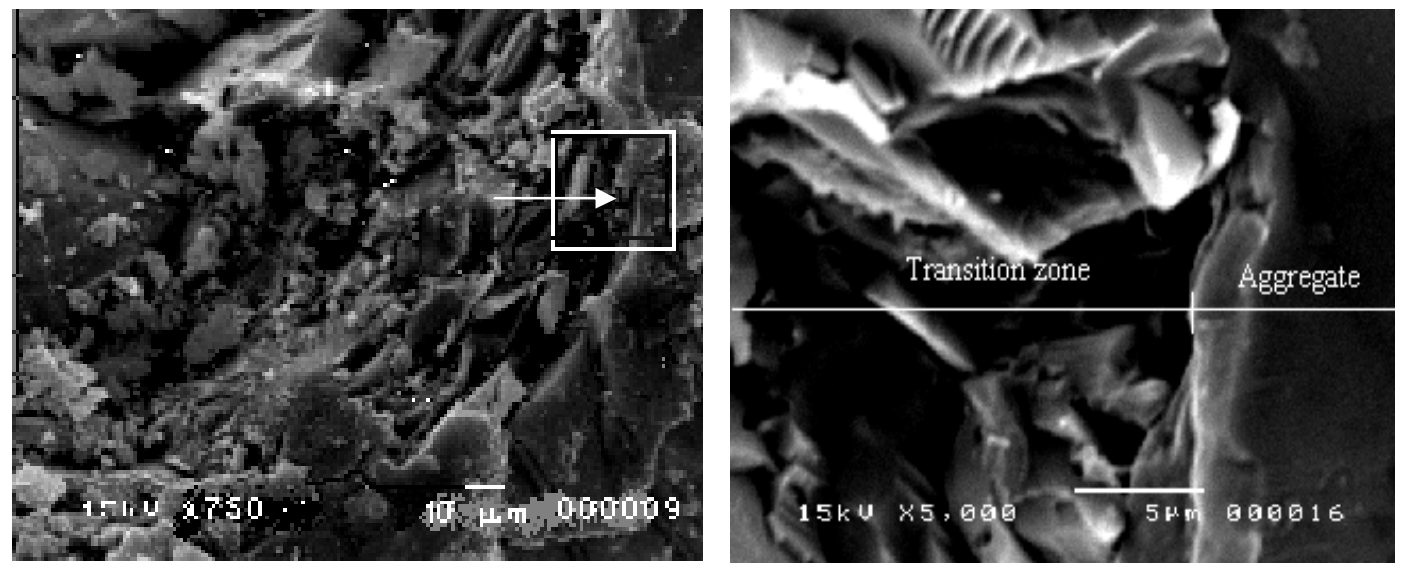

(a)
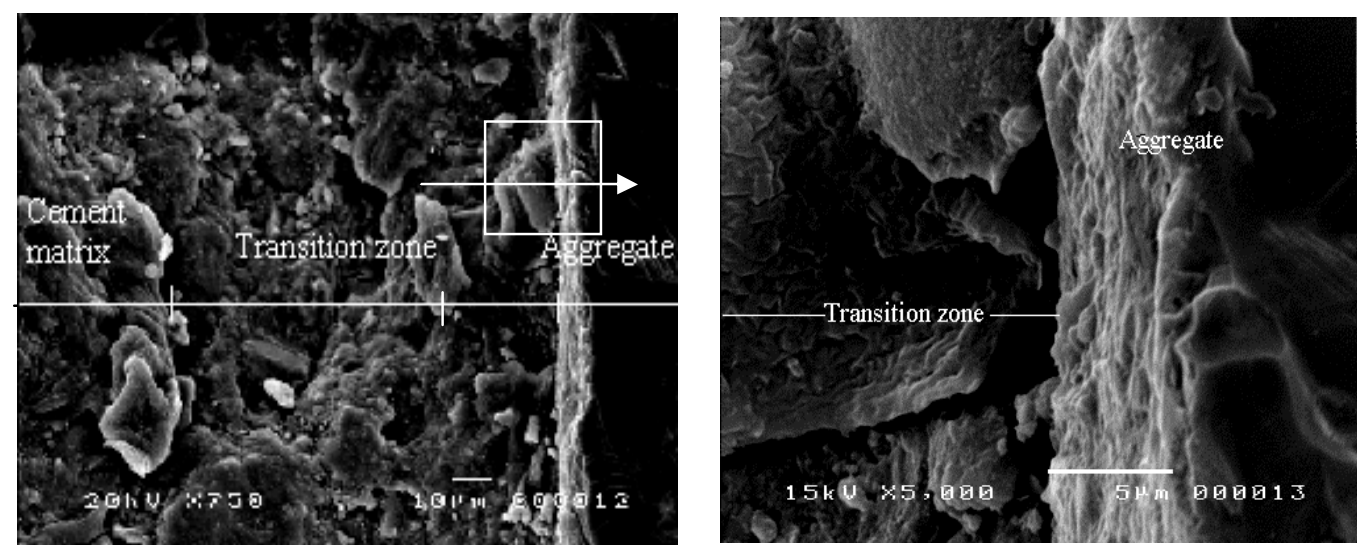

(b)

Fig. 1. The microstructure of transition zone in concrete by use of SEM

(a) Normal concrete; (b) High performance concrete [14]

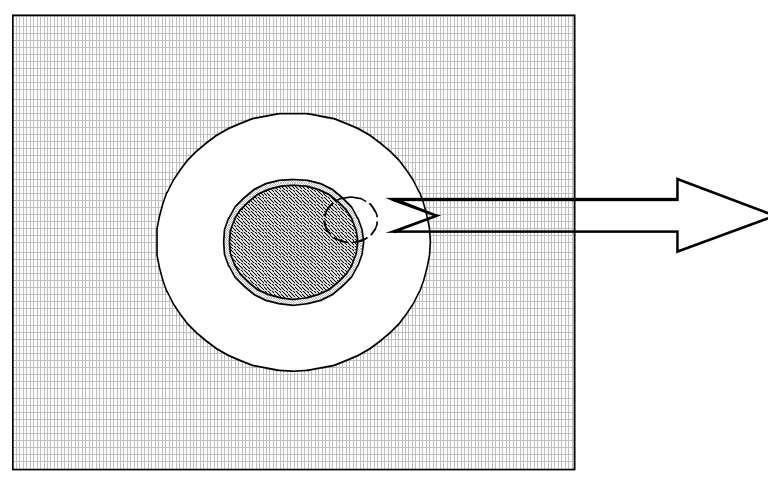

Equivalent homogeneous medium

Mortar

Interface (Non-thickness spring layer)

Coarse aggregate

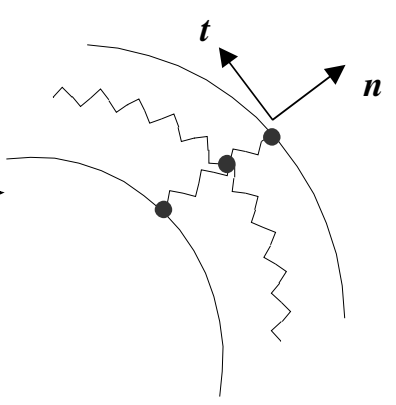

Spring Layer Model

Fig. 2. Three-Phase model with imperfect interface 
interface $\delta \Omega$, which is modeled by an equivalent Somigliana dislocation field [4], we define $S_{i j k l}^{S}$ is

$\left\langle\varepsilon_{i j}^{S}\right\rangle=S_{i j k l}^{S} \varepsilon_{k l}^{*}$

where

$\varepsilon_{i j}^{S}=\frac{1}{2}\left(u_{i, j}^{s}+u_{j, i}^{s}\right)$

Here $u_{i}^{s}$ is the displacement field caused by the interfacial sliding and normal separation. $\left\langle\varepsilon_{i j}^{S}\right\rangle$ is the body average of $\varepsilon_{i j}^{S}$ inside the spherical inclusion:

$\left\langle\varepsilon_{i j}^{S}\right\rangle=\frac{1}{V} \int_{V} \varepsilon_{i j}^{S} d V=\frac{3}{4 \pi R^{3}} \int_{0}^{2 \pi} d \varphi \int_{0}^{\pi} d \theta \int_{0}^{R} \varepsilon_{i j}^{S} r^{2} \sin \theta d r$

If we separate $\varepsilon_{i j}^{S}$ into its hydrostatic and deviatoric components, we can write (12) as

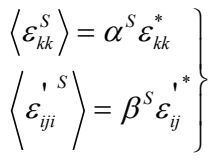

Furthermore, for spherical inclusion, we have

$\varepsilon_{k k}^{p t}=\left(\alpha^{E}+\alpha^{S}\right) \varepsilon_{k k}^{*}$

$\left.\varepsilon_{i j}^{\prime p t}=\left(\beta^{E}+\beta^{S}\right) \varepsilon_{i j}^{\prime{ }^{*}}\right\}$

The perturbation stress can also be divided into two parts

$\sigma^{p t}=\sigma^{E}+\left\langle\sigma^{s}\right\rangle$

In this case, Eshelby's solution for spherical inclusion with perfect interface gives

$\sigma_{i j}^{E}=-\frac{2 \mu_{0}}{45\left(1-v_{0}\right)}\left[10\left(1+v_{0}\right) \varepsilon_{l l}^{*} \delta_{i j}+3\left(7-5 v_{0}\right) \varepsilon_{i j}^{{ }^{*}}\right]$

where $\mu_{0}$ is the shear modulus of cement paste phase, $v_{0}$ Poisson's ratio of cement paste phase, and $\varepsilon_{\mathrm{ij}}{ }^{*}$ is the deviatoric part of $\varepsilon_{\mathrm{ij}}{ }^{*}$.

The stress $\sigma^{\mathrm{S}}$ inside the inclusion [4] is $\sigma_{i j}^{S}=\frac{4 \mu_{0}\left(1+v_{0}\right)}{3\left(1-v_{0}\right)} \lambda_{0} \varepsilon_{l l}^{*} \delta_{i j}+\frac{2 \mu_{0}\left(7-5 v_{0}\right)}{15\left(1-v_{0}\right)} A_{0} \varepsilon_{i j}^{\prime^{*}}+\frac{24 \mu_{0} v_{0}}{5 a^{2}\left(1-v_{0}\right)} B_{0} \varepsilon_{k l}^{\prime^{*}} x_{k} x_{l} \delta_{i j}$ $-\frac{4 \mu_{0}}{35\left(1-v_{0}\right)}\left[2\left(7-4 v_{0}\right) B_{0} \varepsilon_{i j}^{\prime *} \frac{|x|^{2}}{a^{2}}+12 v_{0} B_{0} \varepsilon_{i l}^{\prime *} \frac{x_{l} x_{j}}{a^{2}}+12 v_{0} B_{0} \varepsilon_{j l}^{\prime *} \frac{x_{l} x_{i}}{a^{2}}-\right.$

$\left.2\left(7-10 v_{0}\right) B_{0} \varepsilon_{k l}^{\prime *} \frac{x_{k} x_{l}}{a^{2}} \delta_{i j}-\frac{7}{3}\left(5-v_{0}\right) B_{0} \varepsilon_{i j}^{\prime^{*}}\right]$

where $a$ is the radius of the spherical inclusion (aggregate) defined by $x_{i} \cdot x_{i} \leq a^{2}$ for which $n_{i}=x_{i} / a$. According to Zhong and Meguid's derivation, it is

$\lambda_{0}=\frac{\beta_{0} k_{1}}{3\left(1+\beta_{0} k_{1}\right)}$

$A_{0}=\frac{\alpha_{0} k_{2}+\alpha_{0} \beta_{0} k_{2}\left(k_{3}+k_{4}\right)}{1+\alpha_{0}\left(k_{2}+k_{3}\right)+\beta_{0} k_{4}+\alpha_{0} \beta_{0} k_{2}\left(k_{3}+k_{4}\right)}$

$B_{0}=\frac{\left(\beta_{0}-\alpha_{0}\right) k_{2}}{1+\alpha_{0}\left(k_{2}+k_{3}\right)+\beta_{0} k_{4}+\alpha_{0} \beta_{0} k_{2}\left(k_{3}+k_{4}\right)}$

with

$\alpha_{0}=\frac{\mu_{0} \alpha_{T}}{a}, \quad \beta_{0}=\frac{\mu_{0} \alpha_{N}}{a}$

$k_{1}=\frac{4\left(1+v_{0}\right)}{3\left(1-v_{0}\right)}, \quad k_{2}=\frac{2\left(7-5 v_{0}\right)}{15\left(1-v_{0}\right)}$

$k_{3}=\frac{4\left(7+19 v_{0}\right)}{105\left(1-v_{0}\right)}, \quad k_{4}=\frac{4\left(35+11 v_{0}\right)}{105\left(1-v_{0}\right)}$

We solve the body average of $\sigma^{\mathrm{S}}$, as $\left\langle\sigma_{i j}^{S}\right\rangle=\frac{1}{V} \int \sigma_{i j}^{S} d V=\frac{4 \mu_{0}\left(1+v_{0}\right)}{3\left(1-v_{0}\right)} \lambda_{0} \varepsilon_{l l}^{*} \delta_{i j}+$

$\frac{2 \mu_{0}\left(7-5 v_{0}\right)\left(5 A_{0}+2 B_{0}\right)}{75\left(1-v_{0}\right)} \varepsilon_{i j}^{\prime \text { '* }}$

According to Equation (16), we have

$\left.\begin{array}{rl}\varepsilon^{p t} & =\alpha \varepsilon^{*} \\ \varepsilon^{\prime p t} & =\beta \varepsilon^{\prime *}\end{array}\right\}$

where

$\alpha=\alpha^{E}+\alpha^{S}, \quad \beta=\beta^{E}+\beta^{S}$

$\alpha^{S}=\frac{2\left(1-2 v_{0}\right)}{1-v_{0}} \lambda_{0}, \quad \beta^{S}=\frac{\left(7-5 v_{0}\right)\left(5 A_{0}+2 B_{0}\right)}{75\left(1-v_{0}\right)}$

If $\bar{\sigma}$ denotes the overall average stress tensor and $c_{i}(i$ $=0,1)$ represent the volume fractions of cement paste and aggregate, separately, we have

$\bar{\sigma}=c_{0} \sigma^{(0)}+c_{1} \sigma^{(1)}$

If there is not special statements below, hydrostatic and deviatoric components of the stress and strain tensors will be written as $\sigma$ and $\sigma^{\prime}, \varepsilon$, and $\varepsilon^{\prime}$.

When the geometry of coarse aggregates is considered as sphere, the average stresses in the mortar and the coarse aggregates then follow Eqs. (3), (4), (24), and (27), as

$$
\begin{aligned}
& \sigma^{(0)}=\frac{\kappa_{0}+\alpha\left(\kappa_{1}-\kappa_{0}\right)}{\kappa_{0}+\left(c_{1}+c_{0} \alpha\right)\left(\kappa_{1}-\kappa_{0}\right)} \bar{\sigma} \\
& \sigma^{\prime(0)}=\frac{\mu_{0}+\beta\left(\mu_{1}-\mu_{0}\right)}{\mu_{0}+\left(c_{1}+c_{0} \beta\right)\left(\mu_{1}-\mu_{0}\right)} \bar{\sigma}^{\prime} \\
& \sigma^{(1)}=\frac{\kappa_{1}}{\kappa_{0}+\left(c_{1}+c_{0} \alpha\right)\left(\kappa_{1}-\kappa_{0}\right)} \bar{\sigma} \\
& \sigma^{\prime(1)}=\frac{\mu_{1}}{\mu_{0}+\left(c_{1}+c_{0} \beta\right)\left(\mu_{1}-\mu_{0}\right)} \bar{\sigma}^{\prime}
\end{aligned}
$$

where $\kappa_{i}(i=0,1)$ are the bulk moduli of mortar and coarse aggregates and $\mu_{\mathrm{i}}(i=0,1)$ are the shear moduli of mortar and coarse aggregates. The strains are their forms by

$$
\begin{aligned}
\varepsilon^{(0)} & =\frac{\kappa_{0}+\alpha\left(\kappa_{1}-\kappa_{0}\right)}{\kappa_{0}+\left(c_{1}+c_{0} \alpha\right)\left(\kappa_{1}-\kappa_{0}\right)} \varepsilon^{0} \\
\varepsilon^{(0)} & =\frac{\mu_{0}+\beta\left(\mu_{1}-\mu_{0}\right)}{\mu_{0}+\left(c_{1}+c_{0} \beta\right)\left(\mu_{1}-\mu_{0}\right)} \varepsilon^{, 0}
\end{aligned}
$$

$\varepsilon^{(1)}=\frac{\kappa_{0}}{\kappa_{0}+\left(c_{1}+c_{0} \alpha\right)\left(\kappa_{1}-\kappa_{0}\right)} \varepsilon^{0}$

$\varepsilon^{,(1)}=\frac{\mu_{0}}{\mu_{0}+\left(c_{1}+c_{0} \beta\right)\left(\mu_{1}-\mu_{0}\right)} \varepsilon^{\prime^{0}}$

The body average of the strain can be defined as

$\bar{\varepsilon}_{i j}=c_{0} \varepsilon_{i j}^{(0)}+c_{1} \varepsilon_{i j}^{(1)}+\frac{1}{2 V} \int_{S}\left(\left[u_{i}\right] n_{j}+\left[u_{j}\right] n_{i}\right) d S$

in which $V$ is the volume of whole body [5].

According to Zhong and Meguid's solution, $\left[u_{i}\right]$ can be written as :

$\left[u_{i}\right]=-\lambda_{0} \varepsilon_{l l}^{*} x_{i}-A_{0} \varepsilon_{i j}^{\prime *} x_{j}-\frac{1}{a^{2}} B_{0} \varepsilon_{k l}^{\prime *} x_{k} x_{l} x_{i}$

Substituting Eqs. (32), (33), (34), (35), and (37) into Eqs. (36), we have

$\bar{\varepsilon}=\frac{\kappa_{0}+\left(c_{0} \alpha+c_{1} \lambda_{0}\right)\left(\kappa_{1}-\kappa_{0}\right)}{\kappa_{0}+\left(c_{1}+c_{0} \alpha\right)\left(\kappa_{1}-\kappa_{0}\right)} \varepsilon^{0}$
$\bar{\varepsilon}^{\prime}=\frac{\mu_{0}+\left(c_{1} A_{0}+c_{0} \beta\right)\left(\mu_{1}-\mu_{0}\right)}{\mu_{0}+\left(c_{1}+c_{0} \beta\right)\left(\mu_{1}-\mu_{0}\right)} \varepsilon^{, 0}$ 
Thus we further leads to the effective bulk and shear moduli of the concrete as

$\frac{\kappa}{\kappa_{0}}=\frac{\kappa_{0}+\left(c_{1}+c_{0} \alpha\right)\left(\kappa_{1}-\kappa_{0}\right)}{\kappa_{0}+\left(c_{1} \lambda_{0}+c_{0} \alpha\right)\left(\kappa_{1}-\kappa_{0}\right)}$

$\frac{\mu}{\mu_{0}}=\frac{\mu_{0}+\left(c_{1}+c_{0} \beta\right)\left(\mu_{1}-\mu_{0}\right)}{\mu_{0}+\left(c_{1} A_{0}+c_{0} \beta\right)\left(\mu_{1}-\mu_{0}\right)}$

Due to the isotropy of concrete here, $\kappa$ and $\mu$ known, the Young's modulus $E$ is

$E=\frac{9 \kappa \mu}{3 \kappa+\mu}$

\section{RESULT AND DISCUSSION}

Weibull statistical distribution function has been applied broadly in the field of damage mechanics and concrete failure analysis [5-8]. Lambrigger pointed out Weibull function could correctly characterize the strength and failure of macroscopically homogeneous specimens [9]. Here it is applied to evaluate the failure volume of mortar and interfaces.

In the framework of Mori-Tanaka method, the modulus of concrete is calculated by the procedure in Fig. 3 if only the effect of interfaces is considered.

We assume the volume ratio of aggregates, whose interfaces have been destroyed, conform to a Weibull distribution function. Its form is

$c_{i}(\varepsilon)=1-e^{-\left(\frac{\varepsilon}{\varepsilon_{t h}}\right)^{m}}$

where $c_{i}$ is the volume ratio of interface failure, $\varepsilon$ is the effective strain of concrete. In the state of the pure compressive stress, $\varepsilon$ is equal to $\varepsilon_{3}$. The ' 3 ' means the compressive stress direction. The $\varepsilon_{t h}$ is the strain threshold, in the state of pure compressive stress, it should be equal to the peak strain of concrete, which is corresponding to the strain value when the concrete reaches the ultimate compressive stress (about $\varepsilon_{t h} \approx 0.002$ ). If we consider that $c_{i}$ should be equal to 1 when $\varepsilon$ is equal to $\varepsilon_{t h}$, we normalize Equation (43) and have

$c_{i}(\varepsilon)=\frac{1-e^{-\left(\frac{\varepsilon}{\varepsilon_{t h}}\right)^{m}}}{1-e^{-1}}$

The Weibull distribution can model the distribution of microscopic flaws in the material. The following equation is used to decide the failure volume ratio under the current principal tensile strain.

$c_{m}\left(\varepsilon_{1}\right)=\frac{1-e^{-\left(\frac{\varepsilon_{1}-\varepsilon_{\text {ensilie }}}{\varepsilon_{u}-\varepsilon_{\text {tensile }}}\right)^{m_{m}}}}{1-e^{-1}}$

where $\varepsilon_{1}$ is the first principal tensile strain in mortar, $\varepsilon_{\text {tensile }}$ is a strain threshold value (when $\varepsilon_{1}$ reach the value, the cracks appear in mortar), $\varepsilon_{\mathrm{u}}$ is the maximum tensile value (when $\varepsilon_{1}$ reach the value, the mortar is completely destroyed), $\mathrm{m}_{\mathrm{m}}$ is a shape index.

Here the main failure reason of concrete is considered as the development of microcracks in mortar and interface microcracks. Microcracks in mortar are considered as a series of aligned microcracks. Interface microcracks are considered as a kind of non-thickness spring layer.

In order to calculate the modulus of concrete, firstly, the modulus of mortar is computed. The principal tension causes the initial aligned microcracks arising if the principal tension strain reaches the critical value. These aligned microcracks should be perpendicular to the direction of the principal tension strain. These aligned microcracks are considered as a kind of materials whose modulus is zero.

For the two-phase composite, we have Equation (46) to follow to solve the overall modulus of composite according to Mori-Tanaka method [10].

$L=L_{0}+c_{1}\left[\left(L_{1}-L_{0}\right) T\right]\left[c_{0} \cdot I+c_{1}[T]\right]^{-1}$

with

$T=\left[I+\left(c_{0} . S+c_{1} I\right) L_{0}^{-1}\left(L_{1}-L_{0}\right)\right]^{-1}$

Here subscript 0 represents matrix and subscript 1 is inclusion.

Microcracks in mortar are considered as a kind of aligned crack. They can be modeled as a sort of special constituent in composite: void. So we have

$\bar{L}_{0}=L_{0}+c_{m}\left\{\left(-L_{0}\right) T_{0}\right\}\left[\left(1-c_{m}\right) I+c_{m}\left\{T_{0}\right\}\right]^{-1}$

with

$T_{0}=\left[I+\left(\left(1-c_{m}\right) S_{0}+c_{m} I\right) L_{0}^{-1}\left(-L_{0}\right)\right]^{-1}$

Here $c_{m}$ is the volume ratio of cracks in mortar and 0 represents the material properties of mortar. If there is a series of aligned inclusion in a certain composite (Fig. 4), the corresponding Eshelby's tensor can be given as the following Equation (11):

$S_{0}=\left[\begin{array}{cccccc}0 & 0 & 0 & 0 & 0 & 0 \\ \frac{v_{0}}{2\left(1-2 v_{0}\right)} & \frac{5-4 v_{0}}{8\left(1-v_{0}\right)} & \frac{4 v_{0}-1}{8\left(1-v_{0}\right)} & 0 & 0 & 0 \\ \frac{v_{0}}{2\left(1-2 v_{0}\right)} & \frac{4 v_{0}-1}{8\left(1-v_{0}\right)} & \frac{5-4 v_{0}}{8\left(1-v_{0}\right)} & 0 & 0 & 0 \\ 0 & 0 & 0 & \frac{3-4 v_{0}}{8\left(1-v_{0}\right)} & 0 & 0 \\ 0 & 0 & 0 & 0 & \frac{1}{4} & 0 \\ 0 & 0 & 0 & 0 & 0 & \frac{1}{4}\end{array}\right]$

For the plane stress problem (Fig. 5), Equation (49) can be expressed like below.

$$
S_{0}=\left[\begin{array}{ccc}
0 & 0 & 0 \\
\frac{v_{0}}{2\left(1-v_{0}\right)} & \frac{5-4 v_{0}}{8\left(1-v_{0}\right)} & 0 \\
0 & 0 & \frac{1}{2}
\end{array}\right]
$$

When the principal tension reaches the critical value for cracking, we can calculate the current modulus for concrete. Using Equation (45) to get the current volume ratio of aligned microcracks for mortar, we can get the current modulus of mortar.

When the principal tension reaches the critical value for cracking, we can calculate the current modulus for concrete. Using Equation (45) to get the current volume ratio of aligned microcracks for mortar, we can get the current modulus of mortar.

After the modulus of mortar is calculated, the modulus of concrete can be solved. The volume ratio of interface failure for concrete is calculated by Equation (44). The modulus of concrete is shown as follows.

$L=\bar{L}_{0}+c_{1}\left\{\left(L_{1}-\bar{L}_{0}\right) T\right\}\left\{c_{0} I+c_{1}\{T\}\right]^{-1}$

with

$T=\left[I+\left(c_{0} S+c_{1} I\right) \bar{L}_{0}^{-1}\left(L_{1}-\bar{L}_{0}\right)\right]^{-1}$ 


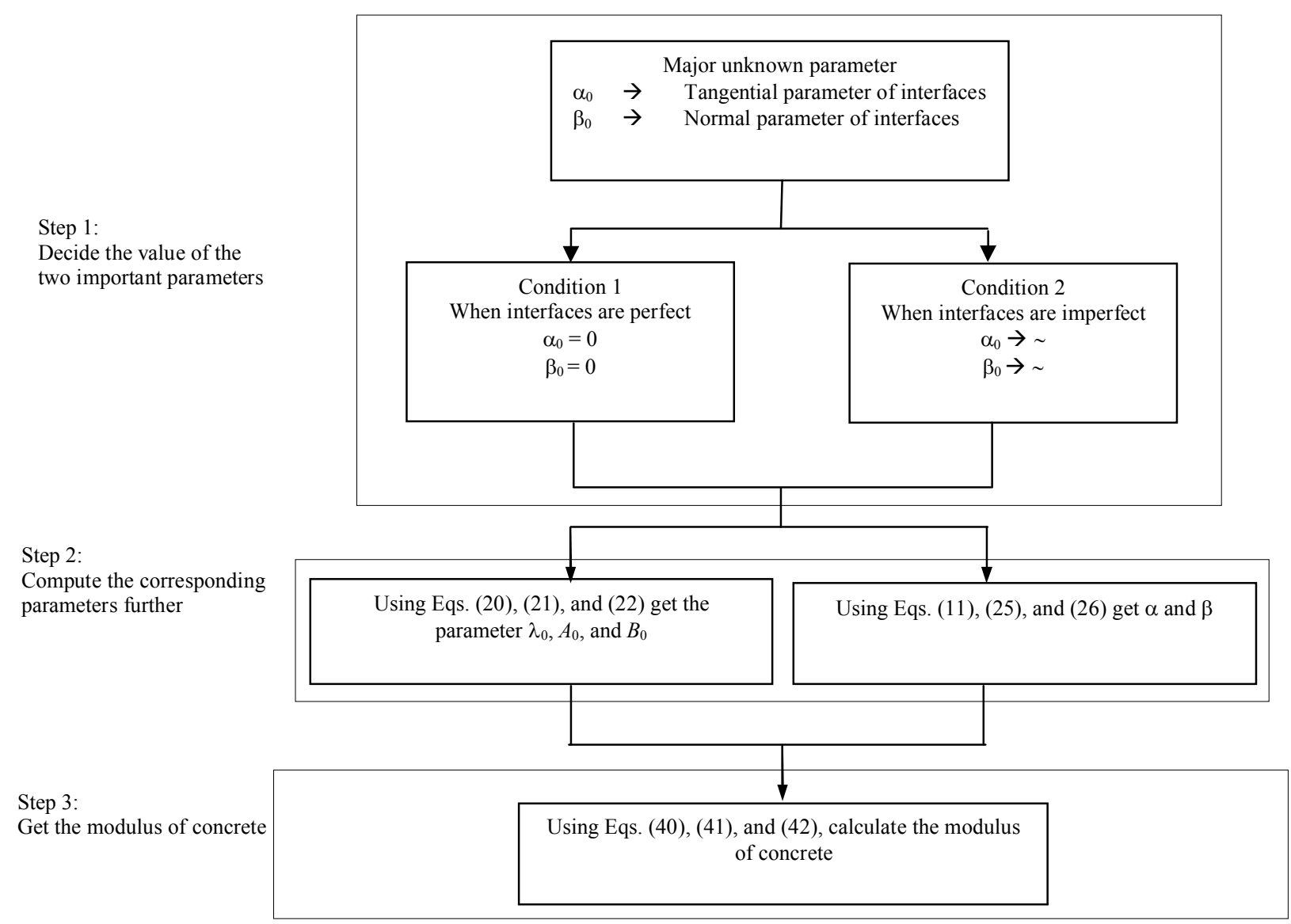

Fig. 3. Outline for calculation of concrete modulus

For the plane stress problem, the Eshelby tensor $S$ can be expressed as the following equation.

$$
S=\left[\begin{array}{ccc}
\frac{\alpha+2 \beta}{3} & \frac{\alpha-\beta}{3} & 0 \\
\frac{\alpha-\beta}{3} & \frac{\alpha+2 \beta}{3} & 0 \\
0 & 0 & \frac{\beta}{2}
\end{array}\right]
$$

For perfect interfaces, we can get the modulus of concrete for perfect interfaces: $L_{p}$. And we can get the modulus of concrete for interfaces destroyed: $L_{d}$.

For a certain load stage, the overall modulus of concrete is

$$
\bar{L}=\left(1-c_{i}\right) L_{p}+c_{i} L_{d}
$$

\section{MODEL PARAMETER}

Here the main parameters are the shape index: $m, m_{m}$, and the threshold value of strain: $\varepsilon_{\mathrm{u}}, \varepsilon_{\mathrm{th}}$. These parameters usually can not be measured directly. Based on simulation for concrete, $m$ and $\varepsilon_{\mathrm{th}}$, related to the interface failure and compression of concrete, are set to 3 and 0.008. $m_{m}$ and $\varepsilon_{\mathrm{u}}$ are related to the mortar failure and tension of concrete and the basic assumption of concrete failure is tensile strain. Here $\varepsilon_{\mathrm{u}}$ is defined as follows [12, $13]$.

$$
\varepsilon_{u}=\frac{2 G_{F}}{f_{t} l_{m}}
$$

where $f_{t}$ is tensile strength for concrete, $G_{F}$ is fracture energy of concrete and $l_{m}$ is eigen-length for mortar. According to CEB-FIP Code (1993), we have the simple empirical formula relating $\mathrm{G}_{\mathrm{F}}\left(\mathrm{J} / \mathrm{m}^{2}=\mathrm{N} / \mathrm{m}\right)$ to the conventional quality control parameter-namely the mean compressive strength of concrete $f_{c}^{\prime}(M P a)$ [7] as $G_{F}=$ $\alpha_{F}\left(f_{c}^{\prime}\right)^{0.7}$. The empirical coefficient $\alpha_{F}$ depends on the maximum aggregate size $g$ (Table 1). Normally, the compressive strength of concrete is given in the common experiment. If the proposed model is used, the tensile strength should be calculated by some empirical equations. There is an empirical formula, which has been suggested by ACI Committee 209 for computing the direct tensile strength of different weight concrete. $f_{t}=\frac{1}{3} \sqrt{w f_{c}^{\prime}}$ psi; $w$ in pcf; and $f_{c}^{\prime}$ in psi

If we change all of the units to SI units, we have the following equation:

$$
f_{t}=0.2187 \sqrt{w f_{c}^{\prime}} \mathrm{kPa} \quad w \text { in } \mathrm{kg} / \mathrm{m}^{3} \text { and } f_{c}^{\prime} \text { in } \mathrm{kPa}(54)
$$

For normal weight concrete, $f^{\prime}{ }_{c}, f_{t}$ are expressed in $\mathrm{MPa}$ by the following equation:

$f_{t}=1.5909 f_{c}{ }_{c}{ }^{l / 2}$

Then the parameter $l_{m}$ should be defined. According to Bazant's random particle model, there is $l_{m}=\beta_{F} . g$ and roughly $\beta_{F}$ is considered to be equal to $1 / 2$. The expression of $\varepsilon_{\mathrm{u}}$ can be written like the following equation.

$\varepsilon_{u}=2.5143 f_{c}^{.0 .2} \frac{\alpha_{F}}{g}$ 
TABLE 1.

COEFFICIENT $\alpha_{F}$ WITH MAXIMUM AgGREGATE SIZE $g$ (KARIHALOO, 1995)

\begin{tabular}{cc}
\hline $\begin{array}{c}\text { Maximum Aggregate Size } g \\
(\mathrm{~mm})\end{array}$ & $\alpha_{F}$ \\
\hline 8 & 4 \\
16 & 6 \\
32 & 10 \\
\hline
\end{tabular}

TABLE 2.

SPECIFIC WEIGHT RATIO FOR MORTAR AND CONCRETE

\begin{tabular}{ccccc}
\hline Grade & Cement & Sand & Water & $\begin{array}{c}\text { Coarse } \\
\text { Aggregate }\end{array}$ \\
\hline $\begin{array}{c}\text { G40 } \\
\text { Mortar }\end{array}$ & 1 & 2.8 & 0.35 & None \\
$\begin{array}{c}\text { GC40 } \\
\text { Concrete }\end{array}$ & 1 & 2.8 & 0.35 & 2.8 \\
$\begin{array}{c}\text { GC50 } \\
\text { Concrete }\end{array}$ & 1 & 2.8 & 0.35 & 1.4 \\
\hline
\end{tabular}

TABLE 3.

ELASTIC PROPERTIES OF G40 MORTAR

\begin{tabular}{cccc}
\hline $\begin{array}{c}\text { Initial Modulus } \\
(\mathrm{GPa})\end{array}$ & $\begin{array}{c}\text { Compressive } \\
\text { Strength } \\
(\mathrm{MPa})\end{array}$ & $\varepsilon_{\mathrm{u}}$ & $m_{m}$ \\
\hline 25.3 & 37.74 & 0.0016 & 1.51 \\
\hline
\end{tabular}

If these parameter values of the certain concrete are given in experiments, the proposed model can predict the stress-strain behavior very well. Studies in this research show the $m_{m}$ is related to the strength of mortar. The stronger the strength of mortar, the larger the value of $m_{m}$ is $\varepsilon_{\mathrm{u}}$ is related to the ductile properties of concrete. The smaller the strength of mortar/concrete, the better the ductile properties of concrete or mortar is so $\varepsilon_{\mathrm{u}}$ is larger. When we do not know the exact value of $m_{m}$ and $\varepsilon_{\mathrm{u}}$, we should use Equations (57) and (58) to calculate them. Here $\varepsilon_{\mathrm{u}}$ is revised as $\varepsilon_{\mathrm{r}}$. For the different strength level, the following equations are recommended to calculate the ultimate tensile strain and $m_{m}$.

$\varepsilon_{r}=3.34-1.59 e^{-3.1 \times 10^{5} \varepsilon_{u}^{-20.48}}$

$m_{m}=8.4-7.55 e^{-0.1 \rho^{3.57}}$

where

$\rho=\frac{\varepsilon_{u}}{\varepsilon_{r}}$

\section{DAMAGE EFFECT}

Here it is worth nothing that the lateral deformation increases significantly at higher stress level after the peak loading point. And the large cracks appear and crack growth becomes unstable. Therefore, the change from volume decrease to sudden volume increases leads to find a proper way for the description of lateral strain during the descending branch. Here the following equation is assumed to modify the behavior of lateral strain after the peak loading point under uniaxial compression.

$\bar{\varepsilon}_{\text {lateral }}=200 e^{-e^{1.667-5 \lambda l}} \varepsilon_{\text {lateral }}$

where

$\lambda_{1}=1-\sigma_{\text {compression }} / f^{\prime}{ }_{c}$
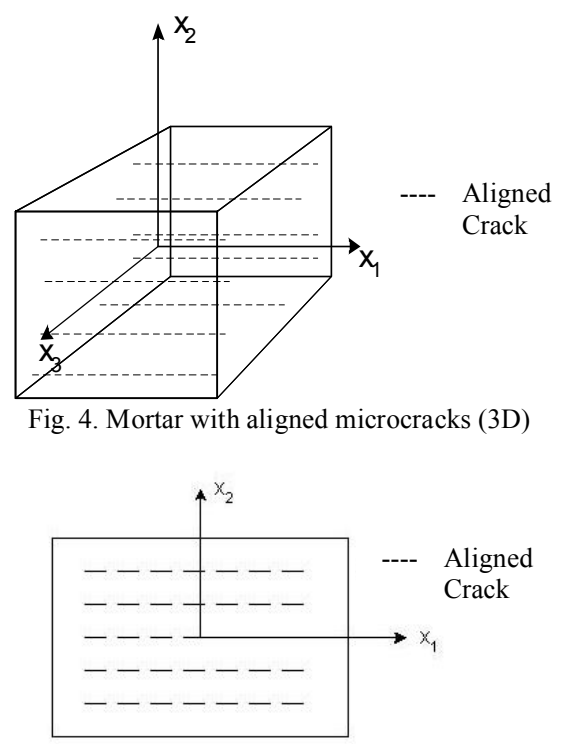

Fig. 5. Mortar with aligned micro cracks

There are some suitable experimental data available [14]. The concrete and mortar are tested. The mortar and concrete were pan-mixed in the laboratory and were cast in steel moulds $(100 \mathrm{~mm}$ in diameter and $200 \mathrm{~mm}$ in height). The mix design is shown in Table 2. The properties of mortar are shown in Table 3.

In Fig. 6, it is shown that the proposed model can predict the mortar behavior very well, especially for the ascending part and the peak point. It is also shown that the aligned microcrack model can properly evaluate the failure of mortar.

The proposed model is further used to predict the compressive behavior of concrete. The volume ratio of mortar and coarse aggregates (Table 4) can be calculated if their densities are known. Here they are assumed. All related data are shown in Table 4. These responses of the predicted compressive behavior are shown in Fig. 7- Fig. 12. These results also show that the comparison for lateral strain does not agree very well. The main reason is that the behavior of concrete in the tensile direction is considered in the model to be that of a continuum material no matter how serious the cracks are.

In order to explore the model capabilities of predicting the transition in behavior from low to high strength concrete, the experimental data for different strength level of concrete are collected in Tables 5 and 6 . In comparison with that obtained experimentally, these predictions are very accurate shown in Fig. 13 and Fig. 14. 


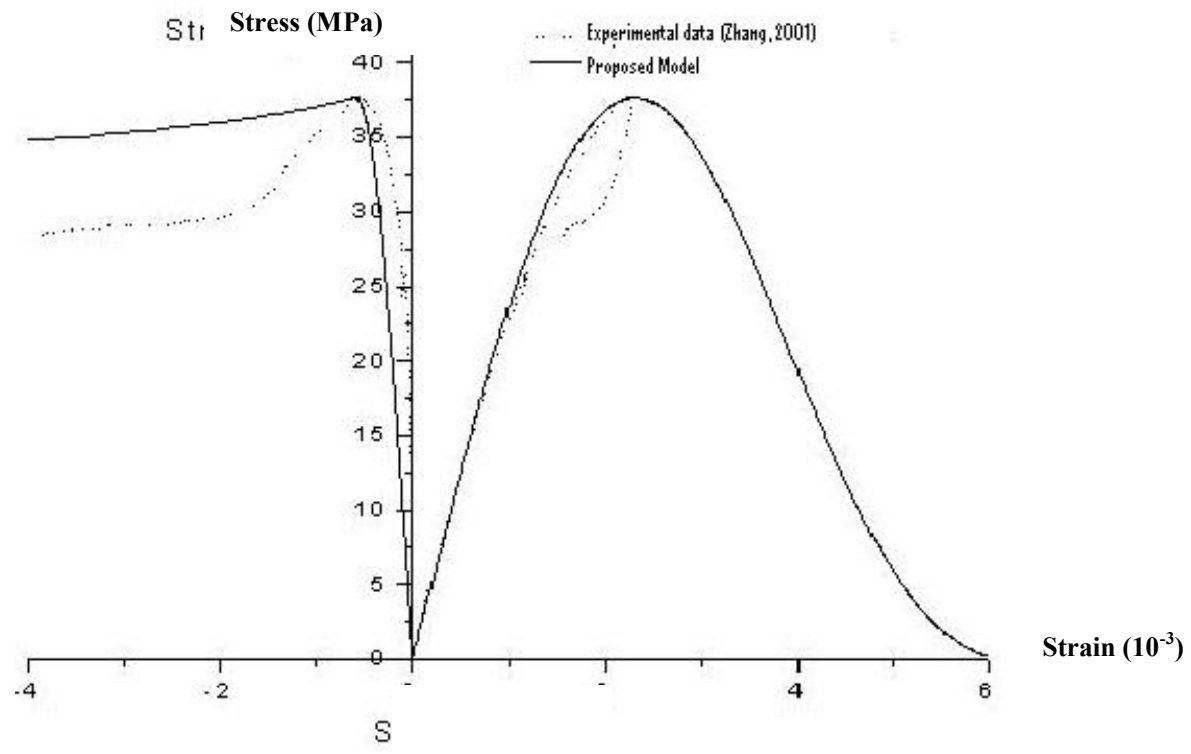

Fig. 6. Stress-Strain curve for mortar

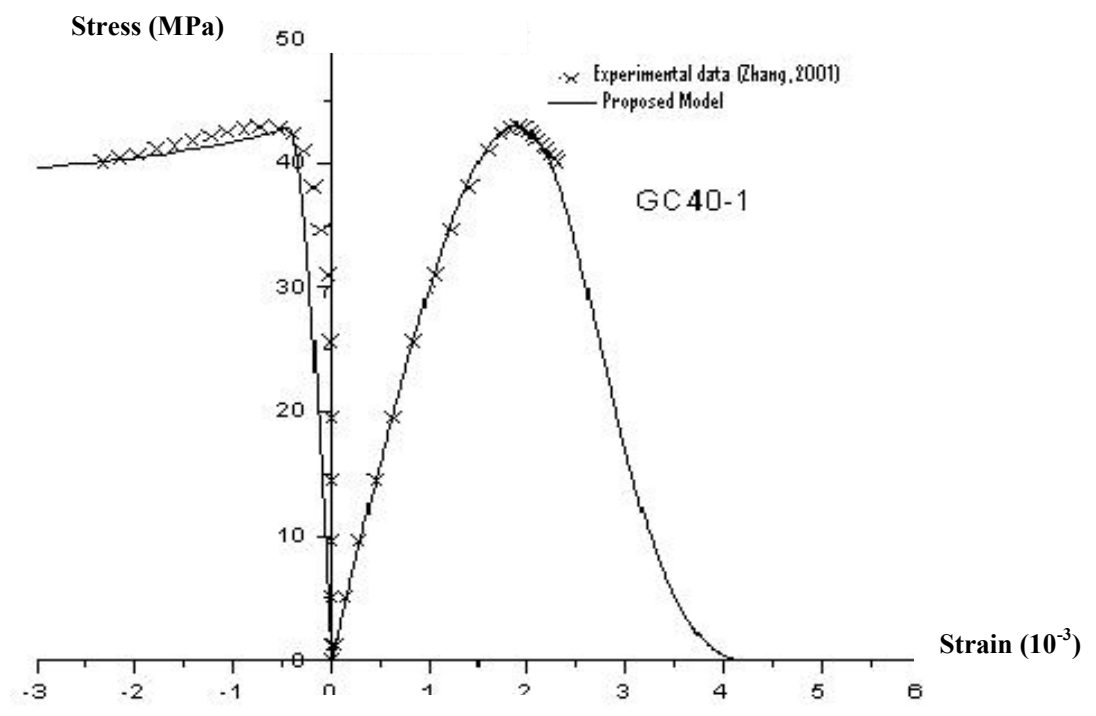

Fig. 7. Stress-Strain relation of concrete GC40-1

Stress (MPa)

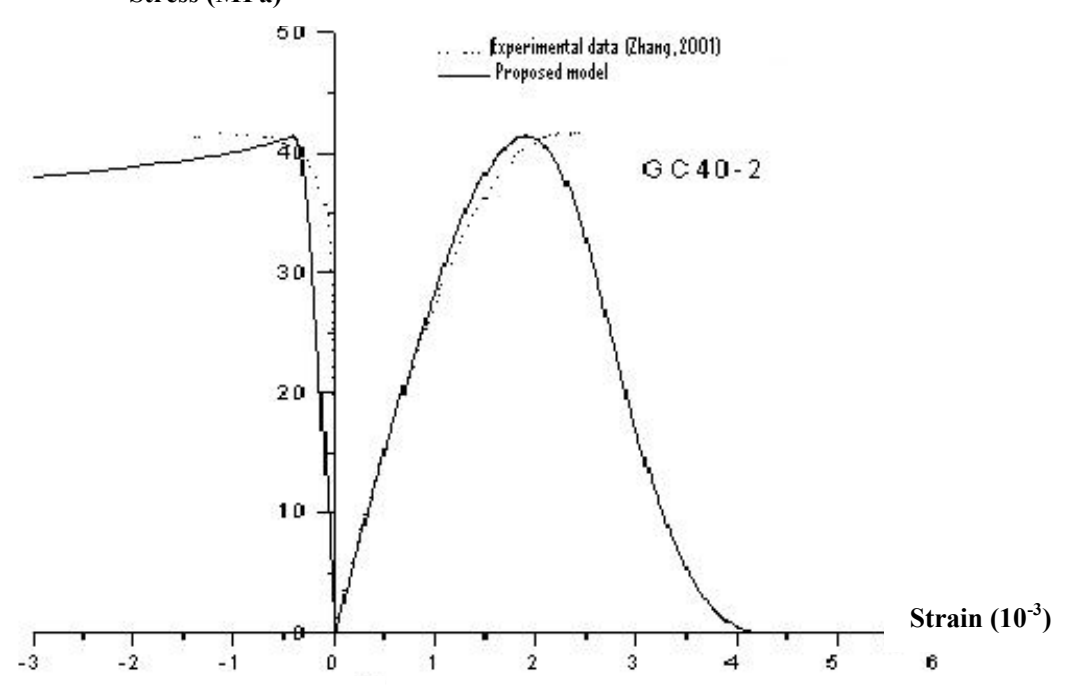

Fig. 8. Stress-Strain relation of concrete GC40-2 


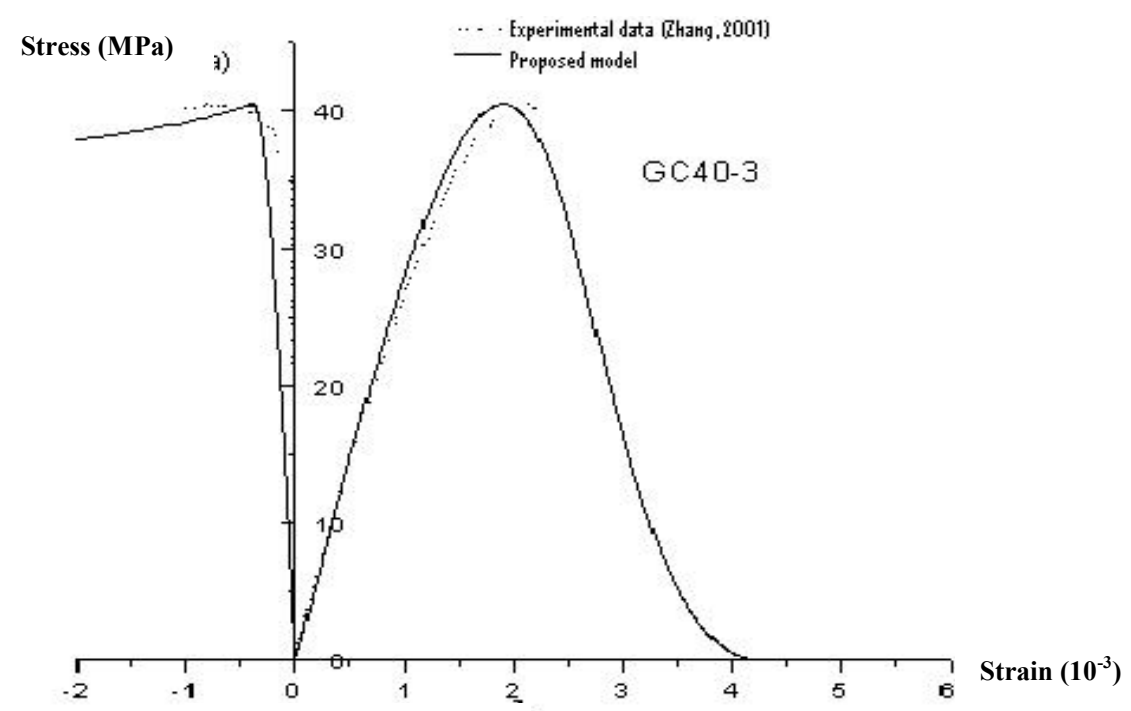

Fig. 9. Stress-Strain relation of concrete GC40-3

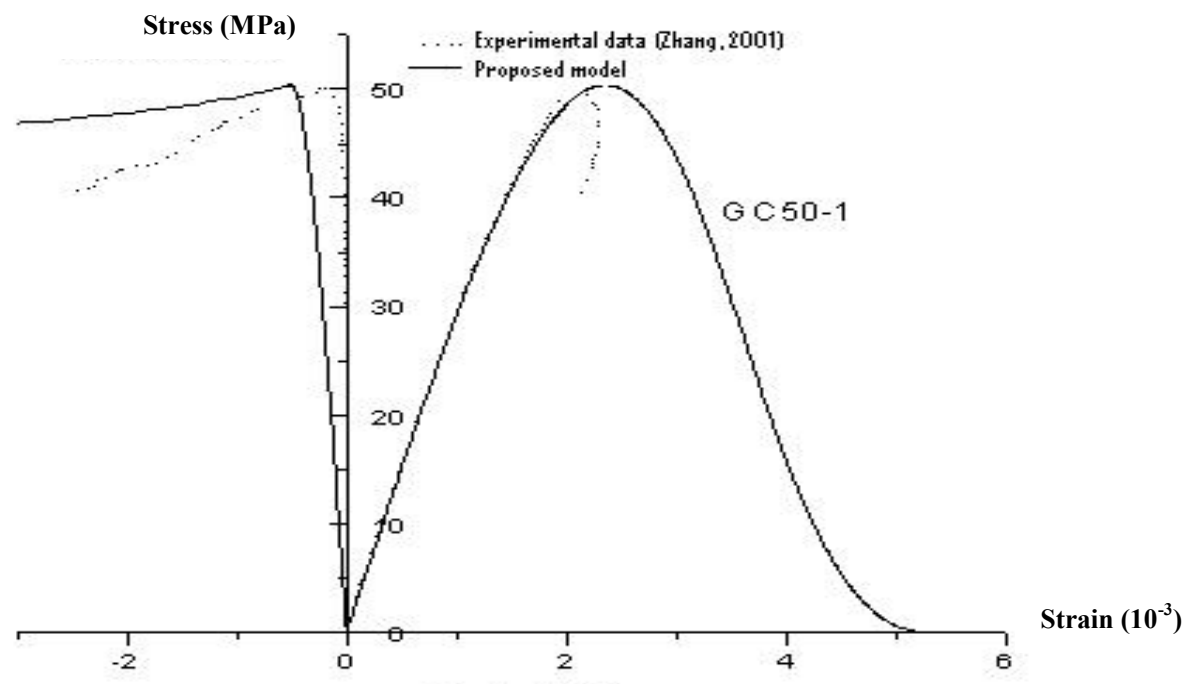

Fig. 10. Stress-Strain curve of concrete 50-1

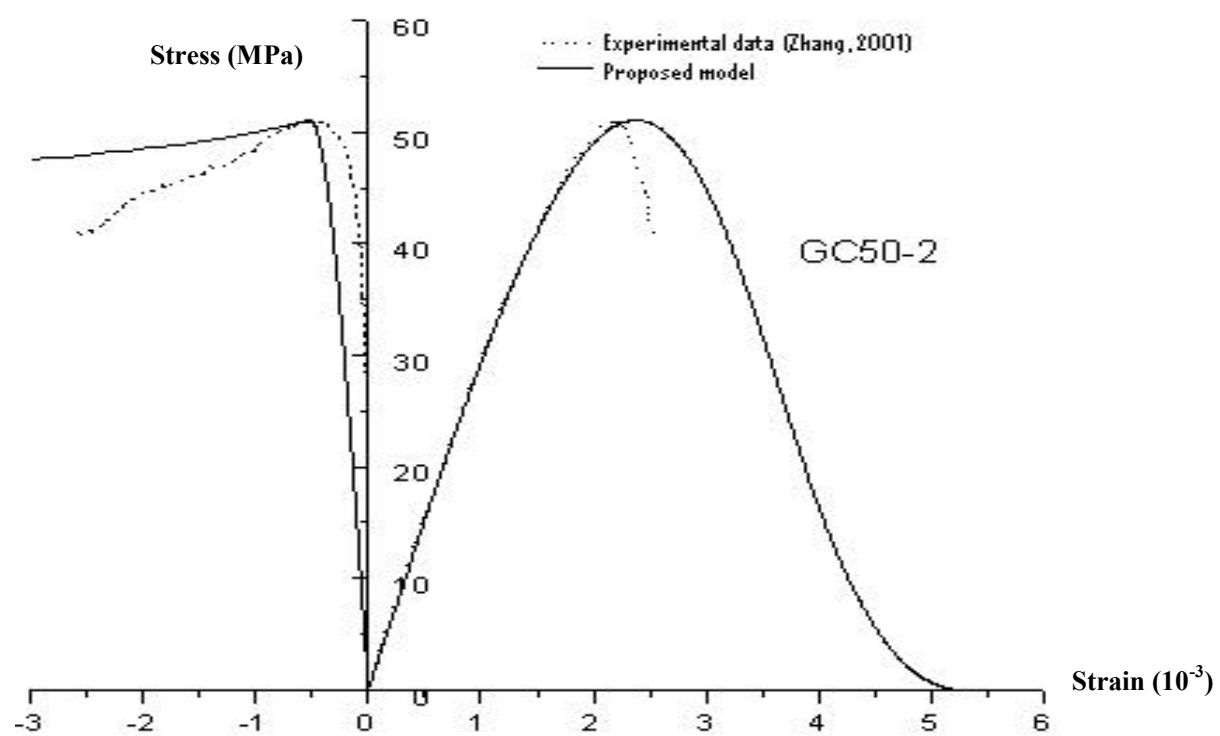

Fig. 11. Stress-Strain curve of concrete 50-2 


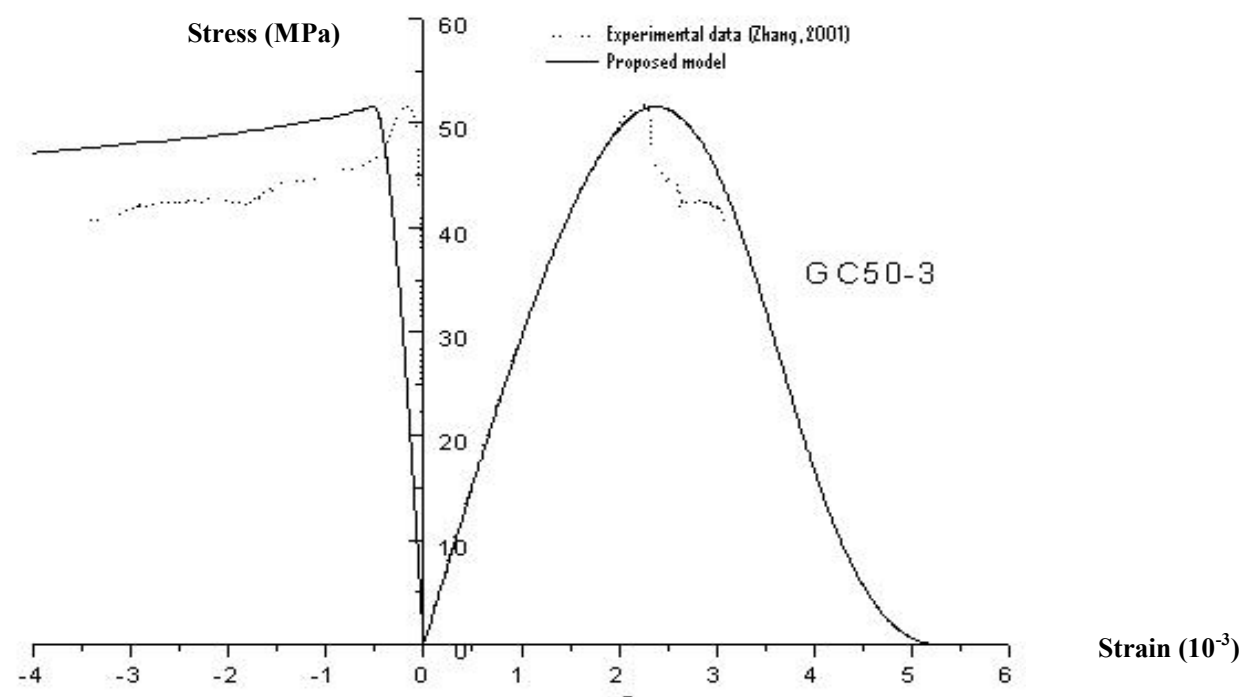

Fig. 12. Stress-Strain curve of concrete 50-3

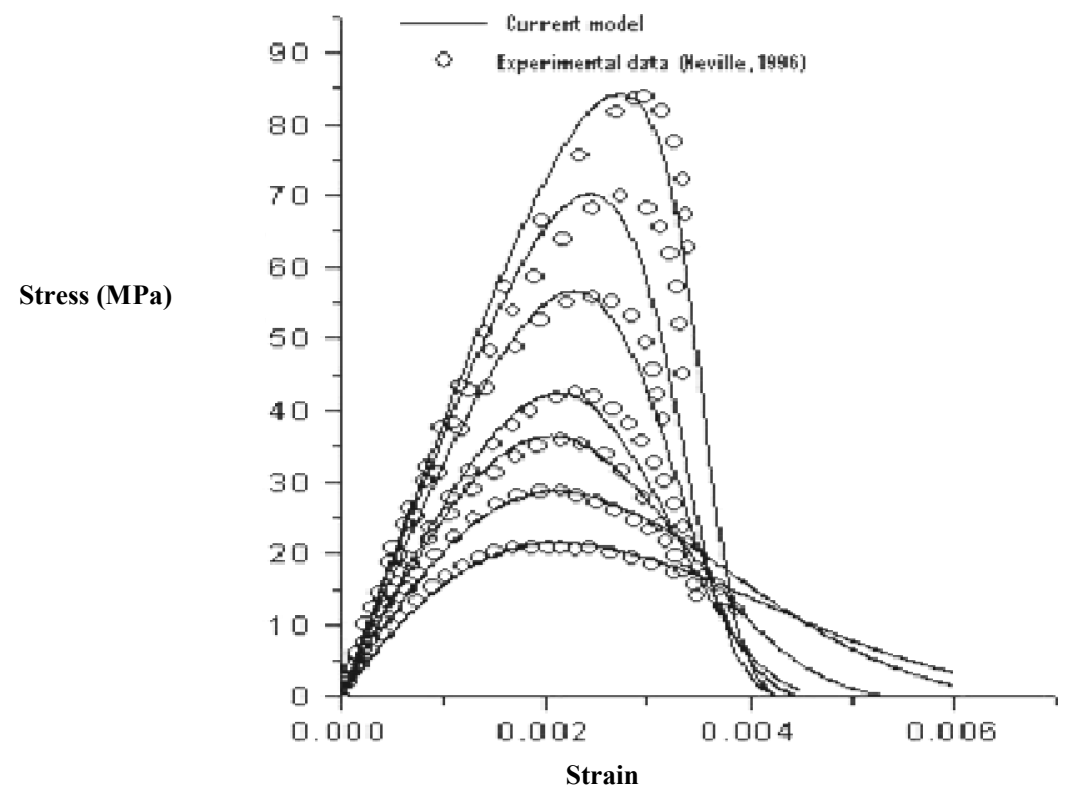

Fig. 13. Stress-Strain curves of different strength for concrete

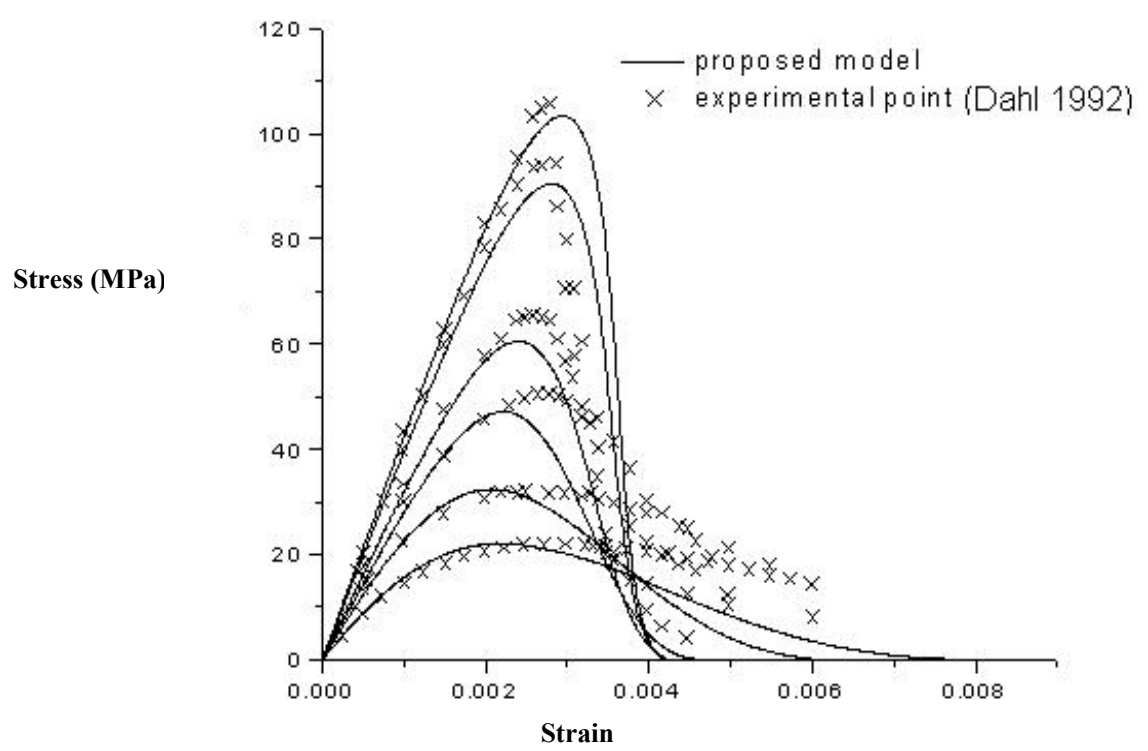

Fig. 14. Stress-Strain curves of different strength for concrete [15] 
TABLE 4 .

PROPERTIES OF CONCRETE

\begin{tabular}{|c|c|c|c|c|c|}
\hline Grade & $\begin{array}{l}\text { Density of Mortar } \\
\text { (assumed) }\left(\mathrm{kg} / \mathrm{m}^{3}\right)\end{array}$ & $\begin{array}{c}\text { Density of Coarse } \\
\text { Aggregates (assumed) } \\
\left(\mathrm{kg} / \mathrm{m}^{3}\right)\end{array}$ & $\begin{array}{l}\text { Volume Ratio } \\
\text { of Mortar }\end{array}$ & $\begin{array}{c}\text { Elastic Modulus } \\
\text { of Concrete } \\
(\mathrm{GPa})\end{array}$ & $\begin{array}{c}\text { Elastic Modulus of Coarse } \\
\text { Aggregates }(\mathrm{GPa})\end{array}$ \\
\hline GC40-1 & 2400 & 2640 & 0.6198 & 32.69 & 50.69 \\
\hline GC40-2 & 2400 & 2640 & 0.6198 & 30.78 & 42.7 \\
\hline GC40-3 & 2400 & 2640 & 0.6198 & 30.25 & 40.69 \\
\hline GC50-1 & 2400 & 2640 & 0.7653 & 31.02 & 63.41 \\
\hline GC50-2 & 2400 & 2640 & 0.7653 & 31.06 & 63.83 \\
\hline GC50-3 & 2400 & 2640 & 0.7653 & 31.31 & 66.57 \\
\hline
\end{tabular}

TABLE 5 .

MAterial Properties AND COEFFiCIENTS FOR THE Proposed Model (NEVILLE, 1996)

\begin{tabular}{|c|c|c|c|c|c|}
\hline$f_{c}^{\prime}(\mathrm{MPa})$ & $E_{c}(\mathrm{GPa})$ & $E_{0}(\mathrm{GPa})$ & $m_{m}$ & $\varepsilon_{u}\left(10^{-3}\right)$ & $\varepsilon_{r}\left(10^{-3}\right)$ \\
\hline 20.8329 & 20.23 & 12.6347 & 0.9 & 1.7307 & 3.3 \\
\hline 28.6999 & 24.66 & 16.6408 & 1 & 1.8452 & 2.9 \\
\hline 35.7387 & 28.28 & 20.3116 & 1.25 & 1.9279 & 2.3 \\
\hline 42.3858 & 30.34 & 21.2075 & 1.6 & 1.9948 & 2 \\
\hline 69.7838 & 37.53 & 31.3671 & 2.1 & 2.204 & 1.8 \\
\hline 83.6917 & 38.98 & 33.3155 & 2.5 & 2.2856 & 1.8 \\
\hline
\end{tabular}

TABLE 6.

MATERIAl Properties AND COEFFiCIENTS FOR THE Proposed MODEL (DAHL, 1992)

\begin{tabular}{cccccc}
\hline$f_{c}^{\prime}(\mathrm{MPa})$ & $E_{c}(\mathrm{GPa})$ & $E_{0}(\mathrm{GPa})$ & $m_{m}$ & $\varepsilon_{u}\left(10^{-3}\right)$ & $\varepsilon_{r}\left(10^{-3}\right)$ \\
\hline 105.8 & 42.85 & 38.786 & 2.815 & 2.395 & 1.758 \\
94.17 & 40 & 34.72 & 2.663 & 2.34 & 1.763 \\
67.4 & 33.3 & 26.013 & 2.219 & 2.189 & 1.802 \\
50.3 & 30 & 22.195 & 1.772 & 2.064 & 1.917 \\
31.7 & 26.6 & 18.563 & 1.092 & 1.882 & 2.578 \\
22 & 20 & 12.441 & 0.93 & 1.75 & 3.28 \\
\hline \multicolumn{7}{c}{ American Society of Mechanical Engineers, Applied Mechanics Division, AMD, Vol. 205, pp. 21-34 }
\end{tabular}

\section{CONCLUSION}

The proposed micromechanical model owns the good capabilities for predicting the entire response of concrete under uniaxial compression. It is suitable that tensile strain is as the criterion of concrete failure and the prediction of crack direction also fits with experimental phenomenon. And Weibull distribution function can describe the behavior of crack development for mortar and interface.

\section{REFERENCES}

[1] G. Ramesh, E. D. Sotelino, and W. F. Chen, 1996, "Effect of transition zone on elastic moduli of concrete materials", Cement and Concrete Research, Vol. 26, No. 4, pp. 611-622.

[2] A. U. Nilsen and P. J. M. Monteiro, 1993, "Concrete: A three phase material", Cement and Concrete Research, Vol. 23, pp. 147-151.

[3] J. Qu, 1993, "The effect of slightly weakened interfaces on the overall elastic properties of composite materials", Mechanics of Materials, Vol. 12, pp. 269-281.

[4] Z. Zhong and S. A. Meguid, 1996, "On the Eigenstrain problem of a spherical inclusion with an imperfectly bonded interface", Journal of Applied Mechanics, Vol. 63, pp. 877-883.

[5] E. P. Chen, 1995, "Dynamic brittle material response based on a continuum damage model", Impact, Waves, and Fracture.
[6] W. Weibull, 1951, "A statistical distribution function of wide applicability", Journal of Applied Mechanics, Vol. 18, pp. 293297.

[7] B. L. Karihaloo, 1995, Fracture Mechanics and Structural Concrete, Longman Scientific and Technical.

[8] W. K. Yip, et al., 1995, "A statistical model of microcracking of concrete under uniaxial compression", Theoretical and Applied Fracture Mechanics, Vol. 22, pp. 17-27.

[9] M. Lambrigger, 1997, "Alternative scaling of cumulative Weibull failure probability distribution functions", Journal of Material Science Letter, Vol. 16, No. 19, pp. 1537-1539.

[10] Y. Benvensite, 1987, "A new approach to the application of Mori-Tanaka's theory in composite materials", Mechanics of Materials, Vol. 6, pp. 147-157.

[11] T. Mura, 1987, Micromechanics of Defects in Solids, Martinus Nijhoff Publishers.

[12] Z. P. Bazant, M. R. Tabbara, M. T. Kazemi, and G. PijaudierCabot, 1990, "Random particle model for fracture of aggregate or fiber composite", Journal of Engineering Mechanics, Vol. 116, No. 8, pp. 1686-1704.

[13] A. R. Mohamed and W. Hansen, 1999, "Micromechanical modeling of concrete response under static loading - Part 1: Model development and validation", ACI Materials Journal, Vol. 96, No. 2, pp. 196-203.

[14] J. G. Zhang, 2001, "Triaxial behaviour of cement mortar under monotonic loading", Master Thesis, Nanyang Technological University.

[15] K. K. B. Dahl, 1992, A constitutive model for normal and highstrength concrete, ABK Report No. R 287, Department of Structural Engineering, TU Denmark, Lyngby. 